\title{
Morfologia dos músculos do ombro, braço e antebraço do quati (Nasua nasua Linnaeus, 1758)
}

\author{
Amilton Cesar dos Santos* \\ Bruno Machado Bertassoli \\ Vanessa Cristina de Oliveira \\ Ana Flávia de Carvalho \\ Ricardo Alexandre Rosa \\ Celina Almeida Furlanetto Mançanares \\ Departamento de Ciência Morfológicas \\ Centro Universitário da Fundação de Ensino Octávio Bastos, Campus II \\ Parque dos Jequitibás, CEP13874-159, São João da Boa Vista - SP, Brasil \\ *Autor para correspondência \\ amiltonsantoss@bol.com.br
}

Submetido em 30/11/2009

Aceito para publicação em 25/06/2010

\section{Resumo}

O quati é um animal que pertence ao Filo Chordata, à Classe Mammalia, à Ordem Carnívora e à Família Procyonidae. A característica marcante da família Procyonidae é a presença de cinco dígitos em seus membros: torácico e pélvico. Estes animais são classificados como plantígrados e podem realizar movimentos manuais em diferentes direções. Possui hábitos de subir em árvores para procriar, fugir do perigo e pernoitar. Alimentase de frutos, pequenos vertebrados, insetos, néctar, ovos e legumes. Para este trabalho foram utilizados três animais eutanaziados provenientes do Criatório Científico (CECRIMPAS) - UNIFEOB, autorizado pelo IBAMA (Processo no 02027.003731/04-76), fixados em solução de formol a 10\%. Neste trabalho foi descrita a morfologia dos músculos do membro torácico do quati, através de dissecação e documentação fotográfica. Nesta espécie, foram encontradas adaptações anatômicas nos músculos dos membros torácicos, que possuem um desenvolvimento volumar mais acentuado que em outras espécies (puma, alpaca, cão, gato, lhama e macaco Cebus apella), e este fato está diretamente relacionado ao seu hábito escalador e habilidade manual.

Unitermos: carnívoros, morfologia, músculo, quati

\section{Abstract}

Morphology of the muscles of the shoulder, arms and forearms of the coati (Nasua nasua). The coati is an animal that belongs to the Phylum Chordata, the Class Mammalia, the Order Carnivora and the Procyonidae family. The striking feature of the family Procyonidae is the presence of five digits on the paws. These animals are classified as plantigrades and can do hand movements in different directions. It has habits of climbing trees to procreate, fleeing from danger, and sleeping at night. It feeds on fruits, small vertebrates, insects, nectar, eggs and vegetables. For this work were used three euthanized animals, from the Scientific Breeding Center 
(CECRIMPAS) - UNIFEOB authorized by IBAMA (Process $n^{\circ} 02027.003731 / 04-76$ ), fixed in formaldehyde solution $10 \%$. This work describes the morphology of the muscles of the forelimb of the coati, through dissection and photographic documentation. In the studied species, we found anatomical adaptations of thoracic limb muscles which had a mass volume much greater than in other species (puma, alpaca, dog, cat, lhama and Cebus apella monkeys), and this fact was found to be directly related to their abilities in climbing and handicraft.

Key words: carnivores, coati, morphology, muscle

\section{Introdução}

O quati (Nasua nasua) é um animal que pertence ao Filo Chordata, à Classe Mammalia, à Ordem Carnívora e à Família Procyonidae (Gray, 1825). A família Procionidae é divida em duas subfamílias: Procioninae e Ailurinae. Os representantes da subfamília Procioninae são chamados de procionídeos e todos habitam o Novo Mundo. Estão divididos em seis gêneros com 18 espécies. Na América do Sul encontram-se quatro gêneros Procyon, Nasua, Potos e Bassaricyon (Denver, 2003).

Os Procionídeos possuem porte médio, pernas curtas, e pelagem densa. São plantígrados, possuem cinco dedos em cada um de seus membros, e, como as suas mãos são móveis possuem habilidade para cavar e são ótimos escaladores (Beisiegel, 2001).

São animas de hábitos diurnos, terrestres e arborícolas. Forrageiam extensivamente no chão, utilizando sua habilidade manual para revirar tocos, pedras e explorar buracos à procura de pequenos invertebrados que compõem sua dieta onívora. As garras longas proporcionam segurança na escalada de árvores. Seu focinho longo e flexível permite explorar ocos de árvores, ninhos de aves e tocas e, por meio do olfato, encontrar pequenos vertebrados. Os frutos também são abundantes em sua dieta e são capturados em seus deslocamentos sobre as árvores. Os quatis utilizam as árvores para nidificarem, repousarem durante a noite e se refugiarem. (Beisiegel, 2001; Teixeira e Ambrósio, 2007).

A época reprodutiva dos quatis acompanha o período de maior abundância de alimentos e sua gestação, dura por volta de 70/80 dias. Nascem entre dois e sete filhotes por gestação, com peso médio de $140 \mathrm{~g}$ e que abrem os olhos por volta do $11^{\circ}$ dia de vida; e com cinco semanas de vida abandonam o ninho e acompanham a mãe em curtas caminhadas. As fêmeas de quatis são matriarcais e vivem com seus filhotes em bandos de até 30 indivíduos; já os machos, quando se tornam adultos, ficam isolados e só se aproximam do grupo na época de acasalamento (Beisiegel, 2001; Teixeira e Ambrósio, 2007).

Os músculos possuem varias funções, como: locomoção, sustentação, respiração, controle da pressão arterial, digestão, reprodução, reserva nutricional, movimentos peristálticos, assim como expressão facial e corporal, ereção dos pêlos, abano da calda, latido, etc. Os músculos são componentes anatômicos individualizados que cruzam uma ou mais articulações, e pela sua contração, são capazes de promover os movimentos. Este movimento é efetuado por células especializadas, denominadas fibras musculares, cuja energia latente é ou pode ser controlada pelo sistema nervoso, sendo capazes de transformar energia química em energia mecânica (St. Clair, 1986; Manzanares, 2007).

Considerando a existência de poucos trabalhos sobre a anatomia do quati e a grande representatividade, tanto numérica quanto geográfica, desta espécie de carnívoros, é importante ressaltar que generalizações quanto ao padrão da anatomia devem ser feitas de maneira cautelosa, visto que poucos espécimes foram estudados detalhadamente.

\section{Material e Métodos}

Foram utilizados três animais (quatis) eutanaziados, provenientes do CECRIMPAS (IBAMA ${ }^{\circ}$ 02027.002322/98-99) do Centro Universitário Fundação de Ensino Octávio Bastos. Estes tiveram a aorta abdominal canulada e injetada com látex Neoprene 650, para repleção do leito arterial e, em seguida, os animais foram fixados em solução aquosa de formaldeído a $10 \%$. 
Para a análise macroscópica, os músculos dos membros torácicos do quati foram dissecados e fotografados in situ. As informações pertinentes à morfologia foram descritas conforme o International Comitee on Veterinary Gross Anatomical Nomenclature (2005).

Foram respeitados os parâmetros Internacionais da bioética e bem estar animal, conforme preconiza a Comissão de Ética da Faculdade de Medicina Veterinária de São João da Boa Vista - UNIFEOB.

\section{Resultados e Discussão}

O músculo deltóide do quati (Figura 1B), assim como o do cão e do gato, descrito por Done et al. (2002), possui duas porções, escapular e acromial, que se originam respectivamente, na espinha e no acrômio da escápula, e se fundem antes de se inserirem na tuberosidade deltóide do úmero. Schaler (1999) descreve que, em eqüinos, as duas porções se fundem, devido à ausência de acrômio na escápula. $\mathrm{O}$ músculo deltóide cobre o músculo infra-espinhoso e possui ação de flexionar o ombro, observa Concha et al. (2004), no puma (Puma concolor).

O músculo infra-espinhoso do quati (Figura 2), semelhante ao puma (Concha et al., 2004), possui origem na fossa infra-espinhosa e se insere na face lateral do tubérculo maior do úmero. Exerce a ação de estender e flexionar a articulação do ombro, dependendo do grau de extensão durante a contração e também abduz o ombro e gira o braço lateralmente (Evans e De Lahunta, 1994). Schaler (1999) descreve ainda, que este músculo funciona como um ligamento colateral lateral da articulação do ombro.

No quati, assim como no cão (St. Clair, 1986), o músculo redondo menor é pequeno e triangular e está localizado caudalmente ao ombro, possui origem no tubérculo infraglenóide e inserção na tuberosidade redonda menor do úmero. Evans e De Lahunta (1994) e Schaler (1999) descrevem que o músculo redondo maior possui ação de flexionar o ombro e rodar lateralmente o braço.
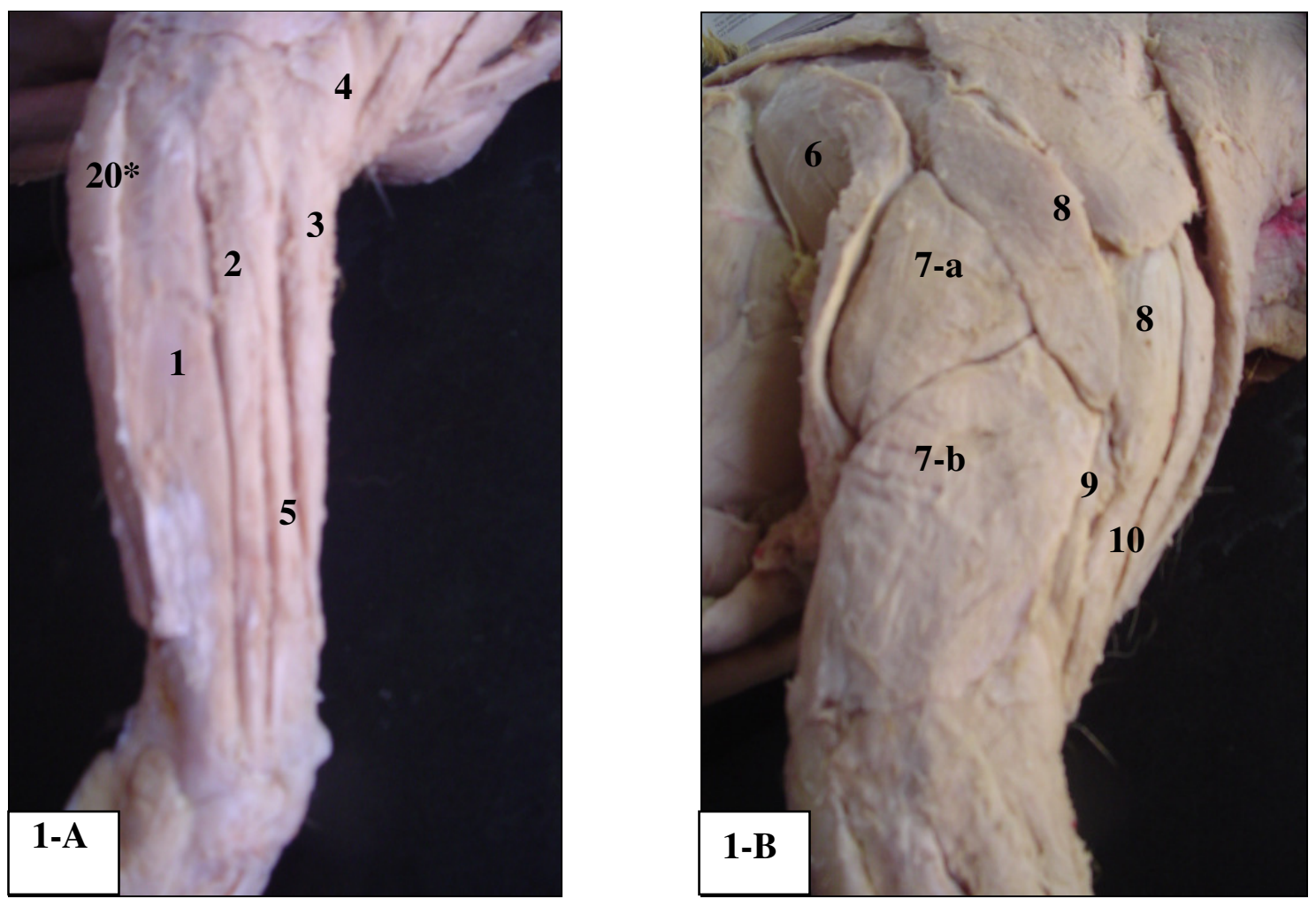

FIGURA 1: A - Antebraço do quati (Nasua nasua) vista lateral: 1 - m. extensor ulnar do carpo; 2 - m. extensor lateral dos dedos; 3 - $\mathrm{m}$. extensor comum dos dedos; $4-\mathrm{m}$. extensor radial do carpo; $5-\mathrm{m}$. abdutor longo do primeiro dedo. B - Braço e ombro do quati vista lateral: 6 - m. redondo maior; 7-a - cabeça longa do $\mathrm{m}$. tríceps braquial; 7-b - cabeça lateral do m. tríceps braquial; $8-\mathrm{m}$. deltóide; $9-\mathrm{m}$. braquial; $10-\mathrm{m}$. bíceps braquial; $20^{*}-\mathrm{m}$. flexor superficial dos dedos. 
A origem do músculo supra-espinhoso do quati, assim como dos cães e gatos (Done et al., 2002) e do puma (Concha et al., 2004), está situada na fossa supra-espinhosa, com uma parte do músculo unida ao músculo subescapular, e sua inserção é por um tendão no tubérculo maior do úmero. Este músculo possui ação de estender o ombro (St. Clair, 1986; Schaler, 1999).

Ocupando toda a fossa subescapular do quati, assim como no puma (Concha et al., 2004), está o músculo subescapular (Figura 2), que possui origem na fossa subescapular e inserção no tubérculo menor do úmero, e possui ação de estender e aduzir o ombro, segundo Evans e De Lahunta (1994). Funciona ainda como um ligamento colateral medial da articulação do ombro (Schaler, 1999).

O músculo redondo maior (Figura 1B) está localizado caudalmente ao músculo subescapular. Origina-se margem caudal da escápula, ventral ao ângulo da escápula e superfície caudal do músculo subescapular, sua inserção está na crista do tubérculo menor do úmero, semelhante à descrição de Schaler (1999). Possui ação de flexionar o ombro e rodar o braço medialmente, no quati, assim como nos carnívoros descritos por St. Clair (1986).

Cruzando obliquamente a face medial da articulação do ombro do quati, está o músculo coracobraquial (Figura 2), que é pequeno e se origina no processo coracóide da escápula através de um tendão, concordando com a descrição de Schaler (1999). Insere-se na crista do tubérculo menor do úmero e, possui ação de aduzir e estender o ombro (Evans e De Lahunta, 1994).

Com quatro cabeças, o músculo tríceps braquial (Figuras 1B e 2), no quati, possui origem na escápula (cabeça longa), distal à cabeça do úmero (cabeça acessória) e na crista do tubérculo menor do úmero (cabeças medial e lateral), semelhante ao pontado no cão (Evans e De Lahunta, 1994) e nos demais carnívoros (Schaler, 1999). A inserção de todas as cabeças se faz em comum na tuberosidade do olécrano. No quati, a ação deste músculo é de mover o cotovelo, semelhante ao cão e gato descrito por Done et al. (2002) e ao puma, de

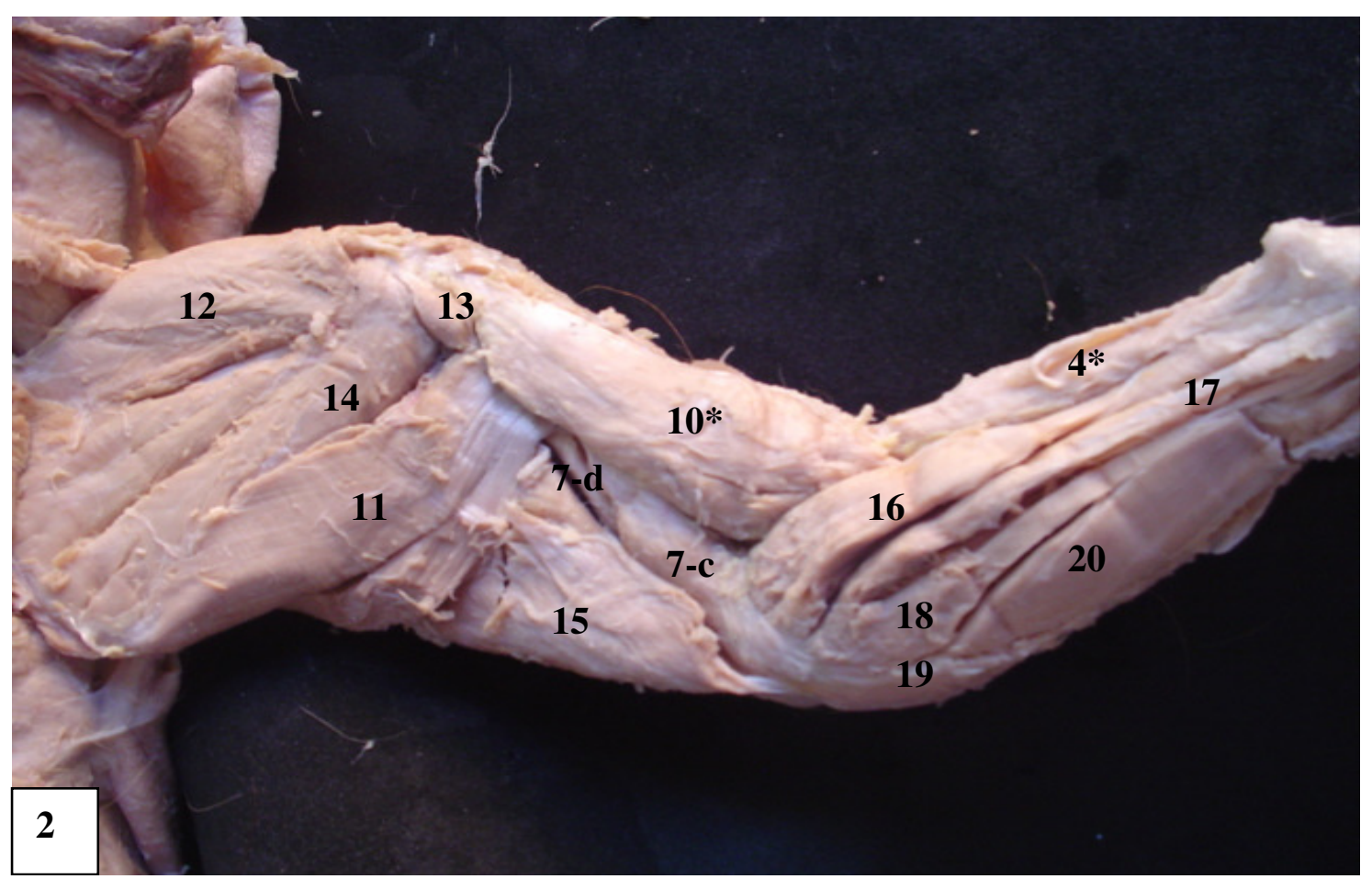

FIGURA 2: Ombro, braço e antebraço do quati (Nasua nasua), vista medial: 11 - m. redondo maior ; 12 - m. supraespinhoso; 13 - m. coracobraquial; $14-\mathrm{m}$. subescapular; $15-\mathrm{m}$. tensor da fáscia ante braquial $16-\mathrm{m}$. pronador redondo; $17-\mathrm{m}$. flexor radial do carpo; 18- m. flexor profundo dos dedos; 19 - m. flexor ulnar do carpo; 20 - m. flexor superficial dos dedos. Note que, na face medial, é possível visualizar as cabeças: acessória (7-d) e medial (7-c) do m. tríceps braquial; m. bíceps braquial (10) e o m. extensor radial do carpo (4*). 
acordo com Concha et al. (2004). No quati, foi verificado um acentuado volume no ventre deste músculo, o que pode estar relacionado ao hábito escalador desta espécie animal (Teixeira e Ambrósio, 2007).

Posicionado sobre a cabeça longa do músculo tríceps braquial, o músculo tensor da fáscia do antebraço do quati (Figura 2), assim como do puma, descrito por Concha et al. (2004), possui origem na fáscia da face lateral do músculo grande dorsal e inserção na tuberosidade do olécrano. Este músculo possui ação de estender o cotovelo (St. Clair, 1986; Schaler, 1999).

O músculo ancôneo é pequeno e está localizado na fossa do olécrano, tanto no quati, quanto no puma (Concha et al., 2004). Sua origem está nos epicôndilos e crista epicondilar do úmero, sua inserção está na face lateral proximal da ulna e possui ação de estender o cotovelo, conforme descrição de Evans e De Lahunta (1994) e Schaler (1999).

Com apenas uma cabeça, o músculo bíceps braquial (Figuras 1B e 2) é longo e fusiforme, possui origem no tubérculo supraglenóide e inserção na tuberosidade ulnar e radial, tanto no quati, quanto no puma (Concha et al., 2004) e nos cães (Tatarunas e Matera, 2006). Este músculo possui ação de flexionar e estender o cotovelo (St. Clair, 1986) e, funciona como fixador da articulação do ombro (Schaler, 1999). E, devido ao hábito escalador do quati (Teixeira e Ambrósio, 2007), podemos sugerir como sendo este o fator que leva a um desenvolvimento muscular maior que nos carnívoros domésticos, descritos por St. Clair (1986).

O músculo braquial do quati (Figura 1B) é longo e possui origem na parte proximal da face lateral do úmero e sua inserção se faz, junto com o músculo bíceps braquial, na ulna e rádio, igualmente ao descrito por Concha et al. (2004) no puma, assim como por Schaler (1999), no cão e no gato. Foi notado um maior volume no ventre deste músculo, comparado com os cães e gatos descritos por Done et al. (2002), devido talvez ao hábito escalador do quati (Teixeira e Ambrósio, 2007).

O músculo extensor radial do carpo (Figura 1A) está situado na face cranial do rádio nos quatis. Possui origem na crista epicondilar lateral e se insere nas tuberosidades proximais e no dorso dos metacarpianos
II e III, e é responsável por estender a articulação do carpo em carnívoros, segundo Schaler (1999). Embora o quati possua habilidades manuais descritas por Beisiegel (2001), não foram notadas diferenças na morfologia deste músculo.

Com quatro tendões se inserindo no processo extensor das falanges distais dos dedos II, III, IV e V, e origem no epicôndilo lateral do úmero, encontra-se o músculo extensor comum dos dedos (Figura 1A), nos quatis ora estudados, assim como no puma (Concha et al., 2004). Este músculo possui ação de estender as articulações interfalângicas dos quatro dedos principais do quati, assim como no cão, conforme descrito por Evans e De Lahunta (1994) e Schaler (1999).

Entre os músculos extensor comum dos dedos e extensor ulnar do carpo do quati, dos cães e gatos descritos por Done et al. (2002) e do puma (Concha et al., 2004), localiza-se o músculo extensor lateral dos dedos (Figura 1A), que possui origem no epicôndilo lateral do úmero e se insere nas faces laterais das extremidades proximais das falanges dos dedos III, IV e $\mathrm{V}$ e no processo extensor das falanges distais desses mesmos dedos. Este músculo possui ação de estender as articulações dos dedos III, IV e V (Evans e De Lahunta, 1994; Concha et al., 2004).

O músculo extensor ulnar do carpo (Figura 1A) do quati, se origina no epicôndilo lateral do úmero e se insere na extremidade proximal ao metacárpico $\mathrm{V}$ e no osso cárpico acessório, assim como nos cães e gatos (Done et al., 2002), e no puma (Concha et al., 2004). Este músculo possui ação de abduzir e flexionar a articulação do carpo nos cães (Evans e De Lahunta, 1994), mas, no quati, pode ter outras funções, devido à sua habilidade manual (Beisiegel, 2001).

Localizado na face lateral da superfície flexora da articulação do cotovelo do quati está o músculo supinador, que possui ação de rotação lateral do antebraço, de modo que a mão gire em supinação e também flexiona o cotovelo (St. Clair, 1986). Este músculo possui origem no epicôndilo lateral do úmero e se insere na superfície cranial na parte proximal do rádio no quati, nos cães (Evans e De Lahunta, 1994) e no puma (Concha et al., 2004). 
No quati o pronador redondo (Figura 2) é um músculo, que se situa entre os músculos extensor radial do carpo e flexor radial do carpo, assim como nos cães e gatos (Done et al., 2002). Tem origem no epicôndilo medial do úmero e se insere na borda medial do rádio, entre a parte proximal e média, igualmente ao descrito por Schaler (1999). Este músculo possui ação de rodar medialmente o antebraço, de modo que a face palmar gire em direção ao solo, além de flexionar o cotovelo (St. Clair, 1986; Concha et al., 2004).

Localizado no sulco entre o rádio e a ulna, no quati, assim como no puma (Concha et al., 2004), se encontra o músculo abdutor longo do primeiro dedo (Figura 1A), que possui origem na borda lateral do corpo da ulna e na membrana interóssea, e sua inserção está na extremidade proximal do metacárpico I. Este músculo abduz o primeiro dedo no quati, assim como em cães e gatos (Done et al., 2002), além do puma (Concha et al., 2004).

O músculo flexor radial do carpo (Figura 2) está posicionado entre os músculos pronador redondo e flexor superficial dos dedos, no quati, assim como no macaco Cebus apella (Aversi-Ferreira et al., 2006). No quati, sua origem é no epicôndilo medial do úmero e borda medial do rádio e a sua inserção está na face palmar da extremidade proximal dos metacárpicos II e III, assim como nos cães (Evans e De Lahunta, 1994). Sua função é de flexionar o carpo e auxiliar na estabilidade, no quati e no puma (Concha et al., 2004). O flexor digital superficial é um músculo bastante volumoso, que possui origem no epicôndilo medial do úmero, inserção na face palmar da falange média dos dedos II ao $\mathrm{V}$, e possui ação de flexionar o carpo. Este achado no quati se assemelha ao que foi descrito no macaco Cebus apella (AversiFerreira et al., 2006).

Com duas cabeças (ulnar e umeral), forma-se o músculo flexor ulnar do carpo (Figura 2). As duas cabeças se inserem no osso cárpico acessório do quati como na lhama (Constantinescu et al., 2008). A cabeça ulnar possui origem na borda caudal do úmero e face medial do olecrano; já a cabeça umeral tem origem no epicôndilo medial do úmero. Possui ação de flexionar o carpo. No quati, este músculo apresenta a mesma morfologia descrita para o puma (Concha et al., 2004) e macaco Cebus apella (Aversi-Ferreira et al., 2006).

O músculo flexor profundo dos dedos (Figura 2), no quati como no puma (Concha et al., 2004) e da lhama (Constantinescu et al., 2008), possui três cabeças (umeral, radial e ulnar), com origens na cabeça do úmero no rádio e na ulna, com uma inserção comum, localizada no osso cárpico acessório. Sua ação é de flexionar o carpo e as articulações interfalângicas, como descritas por Schaler (1999). No quati, que é plantígrado, esse músculo pode auxiliar na escavação de tocas, assim como na busca de alimentos dentro de ocos, já que ele possui habilidades manuais (Beisiegel, 2001).

O músculo flexor superficial dos dedos do quati (Figura 2) se encontra caudal ao músculo flexor profundo dos dedos. Sua origem é no epicôndilo medial do úmero, e sua inserção na falange proximal dos dedos I à IV. Posicionamento semelhante ao encontrado no quati, foi encontrado nos cães e gatos descritos por Done et al. (2002), e no puma descrito por Concha et al. (2004).

Preenchendo o espaço entre a ulna e o rádio, e com fixações nas superfícies opostas desses ossos, encontra-se o músculo pronador quadrado no quati, assim como nos cães e gatos descritos por Done et al. (2002), no puma descrito por Concha et al. (2004) e no macaco Cebus apella (Aversi-Ferreira et al., 2006). Este músculo possui ação de pronação da mão, auxiliando o quati a revirar buracos na busca de alimentos, além da capacidade de manipular os mesmos (Beisiegel, 2001).

\section{Agradecimentos}

À UNIFEOB pelo incentivo à produção científica e à FAPESP por permitir a dedicação à pesquisa em período integral do autor principal.

\section{Referências}

Aversi-Ferreira, T. A.; Vieira, L. G.; Pires, R. M.; Silva, Z.; PenhaSilva, N. 2006. Estudo anatômico dos músculos flexores superficiais do antebraço no macaco Cebus apella. Bioscience Journal, 22 (1): 139-144. 
Beisiegel, B. M. 2001. Notes on the coati, Nasua nasua (Carnívora: Procyonidae) in an Atlantic Forest area. Brazilian Journal of Biology, 6 (4): 689-692.

Concha, I.; Adaro, L.; Borrón, C.; Altamirano, C. 2004. Consideraciones anatómicas sobre la musculatura intrínseca del miembro torácico del puma (Puma concolor). International Journal of Morphology, 22 (2): 121-125.

Constantinescu, G. M.; Reed, S. K.; Constantinescu, I. A. 2008 The suspensory apparatus and digital flexor muscles of the llama (Lama glama) 1: The thoracic limb. International Journal of Morphology, 26 (3): 543-550.

Denver, M. 2003. Procionidae and Viverridae. In: Fowler, M. $\&$ Miller, R. E. (Eds). Zoo and Wild Animal Medicine. $5^{\text {th }}$ ed Saunders, Missouri, USA, p.516-523.

Done, S. H.; Goody, P. C.; Evans, S. A.; Stickland, N. C. 2002. Atlas colorido de anatomia veterinária do cão e do gato. Manole, Barueri, Brasil, 275pp.

Evans, E.; de Lahunta, A. 1994. Guia para a dissecção do cão. $3^{\mathrm{a}}$ ed. Guanabara Koogan, Rio de Janeiro, Brasil, 206pp.
International Comitee on Veterinary Gross Anatomical Nomenclature. 2005. Nomina Anatomica Veterinaria. $5^{\text {th }}$ ed. Hannover, Columbia, Gent, Sapporo, USA, 165pp.

Manzanares, M.A. 2007. Adaptaciones musculares relacionadas a áreas corporales que participan activamente en el vuelo de Anhima cornuta (Aves: Anseriformes, Anhimidae). Revista Peruana de Biologia, 14 (1): 145-150.

Schaler, O. 1999. Nomenclatura anatômica veterinária ilustrada. Manole, São Paulo, Brasil, 576pp.

St. Clair, L. E. 1986. Músculos do carnívoro. In: Getty, R. D. V. M. (Ed.). Anatomia dos animais domésticos. v.2. Guanabara Koogan, Rio de Janeiro, Brasil, 2000pp.

Tatarunas, A. C.; Matera, J. M. 2006. Tenotomia artostrópica do músculo bíceps braquial em cádaveres de cães. Ciência Rural, 36 (6): 1824-1829.

Teixeira, R. H. F.; Ambrósio, S. R. 2007. Carnívora-Proyonidae. In: Cubas, Z. S.; Silva, J. C. R. \& Dias, J. C. (Eds). Tratado de animais selvagens. Roca, São Paulo, Brasil, p.571-573. 